\title{
The coherent large-scale circulation change between dry/wet years over central eastern China simulated by NCAR CAM5
}

\author{
Siyao Zhao ${ }^{1}$ Haoming Chen ${ }^{1} \cdot \operatorname{Rucong} \mathrm{Yu}^{1} \cdot \operatorname{Jian} \mathrm{Li}^{1} \cdot \mathrm{Yi}$ Zhang ${ }^{1}$
}

Received: 20 February 2016 / Accepted: 12 October 2016 / Published online: 22 October 2016

(C) The Author(s) 2016. This article is published with open access at Springerlink.com

\begin{abstract}
This study evaluates the simulation of the coherent circulation structure correspond to the changes of midsummer (July-August) rainfall over eastern China $\left(30^{\circ}-40^{\circ}\right.$ $\left.\mathrm{N}, 110^{\circ}-120^{\circ} \mathrm{E}\right)$ in high-resolution NCAR CAM5. Forced by historical sea surface temperatures (SSTs), the NCAR CAM5 reasonably reproduces coherent changes of temperature and large-scale circulations, corresponding to the changes in rainfall. Results show that when the rainfall decreases over eastern China, the model reproduces a remarkable warm center in the upper troposphere with an anomalous anticyclone appears above and an increase in anomalous westerlies to its north. An anomalous anticyclone also occurs in the lower troposphere, along with anomalous southerlies to its east which indicates strengthening of the East Asian summer monsoon. Both the circulation changes in the upper and lower troposphere favor a decrease in precipitation over central eastern China. There were also good correlations between the simulated upper-tropospheric temperature and other large-scale circulation changes. There are some deficiencies in the NCAR CAM5 simulations in terms of the changes in magnitude and location of the rainfall centers. However, in general, the model reasonably reproduced the coherent configuration of the largescale circulation patterns and surface rainfall. This study further confirms that the climate variations across East Asia most likely arise from a regional response to global climate change. The well-simulated configuration by NCAR CAM5 also indicates the reliability of the model and its potential to reveal the
\end{abstract}

Haoming Chen

chenhm@camscma.cn

1 State Key Laboratory of Severe Weather, Chinese Academy of Meteorological Sciences, No 46 Zhongguancun South Street, Beijing 100081, China mechanisms driving the coherent changes of the East Asian summer monsoon system.

\section{Introduction}

The East Asian summer monsoon (EASM) affects China, Japan, and Korea from the subtropics to the mid-latitudes (the "EASM region"); it is influenced by the Tibetan Plateau and complex land-sea distributions in the region, which make it hard to elucidate the mechanisms that drive its variation. The summer rainfall distribution, seasonal movement of the rain belt, and droughts and floods in the EASM region are controlled, to a large extent, by the EASM. The characteristics of the monsoon climate and geography of China cause unique regional precipitation characteristics across China. These variations in precipitation have been an important part of meteorology and climate research for decades (Ding 1992).

The climate variability and predictability (CLIVAR) program has specified 10-100 year timescale climate variation as a vital component of climate research and considers interdecadal precipitation changes as one of the key issues (Ding et al. 2008; Wang 1994; Wang 1997). Affected by interdecadal changes of the EASM, summer rainfall in eastern China also manifests significant interdecadal changes over the past 50 years (Chen et al. 2004; Ding and Chan 2005); for example, in the late 1970s, changes in eastern China rainfall showed the notable "southern-flood-northern-drought" (SFND) pattern (Wang 2001; Zhou et al. 2009a), along with the weakening of the EASM (Du et al. 2009) and the southward shift of the subtropical westerly jet (Ding et al. 2010; Huang et al. 1999; Yu and Zhou 2007; Zhang et al. 2003). Yu et al. (2004) suggested that the SFND anomalous pattern was part of a coherent three-dimensional (3-D) structure, characterized by a cooling trend in the upper troposphere above East 
Asia. It was probably influenced by the North Atlantic Oscillation (NAO), troposphere-stratosphere interactions and snow cover levels on the Tibetan Plateau (Baldwin et al. 2003; Ramaswamy et al. 2001; Xin et al. 2010; Yu and Zhou 2004). At the beginning of the twenty-first century, the global warming rate has slowed down (Trenberth and Fasullo 2013; Trenberth et al. 2014); in contrast to the rapid global warming session before, the East Asian climate has manifested several brand new features. Zhao et al. (2015) found that over eastern China, the mid-summer precipitation has increased over the Huaihe river valley and decreased in the regions south of the middle and lower reaches of the Yangtze River Valley. Accompanied with the interdecadal coherent changes of the 3-D large-scale circulation structure which manifested as an increasing temperature in the upper troposphere above East Asia, a strengthening of the EASM and the northward movement of the subtropical westerly jet.

Precipitation is a critical element of the East Asian climate, but accurate predictions of the EASM rainfall have always been difficult. Researches showed that rainfall simulations in most current climate models are not entirely satisfactory (Chen and Frauenfeld 2014; Zhou et al. 2010), and among them the EASM system simulation is a relatively challenging part (Zhou et al. 2009c). Wang et al. (2005) suggested that the imperfect rainfall simulations in the atmospheric general circulation models (AGCM) may be due to the neglect of the airsea interaction. However, considering the complexity and particularity of the EASM system, the good (to a certain extent) abilities of climate models to predict large-scale circulation have led to their wide application in attribution research of East Asian interdecadal climate change and may have provided an indispensable tool for the EASM climate research (Dai 2010; Ding et al. 2007; Menon et al. 2002; Zhou et al. 2009b).

Before applying climate models in attribution research of interdecadal climate change, we need a clear understanding of their performance. Many researchers have pointed out deficiencies on model simulation of the East Asian precipitation interdecadal changes (Chen 2014; Sun and Ding 2008; Wang et al. 2005). The performance of climate models in simulating interdecadal changes of the EASM has always been evaluated separately either on precipitation or on circulation before (Menon et al. 2002; Wang et al. 2008; Zhou et al. 2009a), merely as a whole structure. Li et al. (2010) carried out a series of experiment using CAM3 and AM2.1 and successfully reproduced the weakening of the EASM in the 1970s. However, they did not provide a realistic simulation of the rainfall changes. Chen et al. (2012) comprehensively assessed the performance of the Beijing Climate Center atmospheric general circulation model (BCC_AGCM) to simulate interdecadal changes in rainfall and the corresponding largescale environment for the late 1970s. Their results showed that although the climate model has deficiencies in simulating variations in the EASM, it can reproduce coherent changes of the
EASM circulation system and precipitation. Their study provides a basis for interdecadal climate change research, based on the climate model.

Wang et al. (2005) suggested that the relatively low model resolution may lead to errors in simulating China rainfall because it fails to capture the complex terrain. As recent progress in model development has led to the production of highresolution models, the model skill on simulating the rainfall pattern over China has been improved to a certain extend. Rainfall distributions over and around the high elevations of the Tibetan Plateau and high-altitude mountains are more realistic in these new high-resolution models (Feng et al. 2011; Kusunoki et al. 2006; Li et al. 2015). However, there has been insufficient study dedicated to evaluating the performance of the high-resolution models in simulating the interannual and interdecadal changes of the EASM and comprehensively evaluating their ability to simulate the latest climate changes over East Asia.

While the EASM system has recently experienced a new interdecadal change (since the turn of the century, under the background of a global warming hiatus), the rainfall of eastern China exhibits significant different patterns compared to the late 1970s as well as the large-scale circulation. Still, there have been few researches dedicated to the skill of highresolution model on comprehensively simulating both the brand new rainfall pattern and its corresponding large-scale circulation changes.

This study focuses on the performance of the National Center for Atmospheric Research Community Atmosphere Model, version 5.1 (NCAR CAM5). As previously mentioned, climate models have deficiencies in reproducing the interdecadal change of East Asia (Qian and Giorgi 1999; Zhou and $\mathrm{Yu}$ 2006; Zhou et al. 2008). In this paper, our main purpose is to investigate whether the NCAR CAM5 can reproduce the integrated 3-D large-scale circulation structure changes over East Asia corresponding to the rainfall pattern variation. Due to the flaws of the model skill on capturing the interdecadal climate change over East Asia, the composite analyses are applied in this study. Such analyses contribute to an appreciation of the models' strengths and deficiencies on simulating climate changes and provide a foundation for EASM research. The rest of the paper is organized as follows. Section 2 provides a brief description of the NCAR CAM5 model and data sets used. The model simulation results are given in Sect. 3, and conclusions and discussion are provided in Sect. 4.

\section{Numerical experiment and data sets}

The NCAR CAM5 model uses the Eulerian dynamical core. The hybrid pressure-sigma vertical coordinate of the model has 30 levels with a top at $2.255 \mathrm{hPa}$. The major model 
physics of CAM5 include the following: (1) separate deep (Richter and Rasch 2008; Zhang and McFarlane 1995) and shallow (Park et al. 2014) convection schemes and a moist turbulence scheme (Bretherton and Park 2008) for calculating the subgrid vertical transport of heat and moisture; (2) a twomoment cloud microphysics scheme (Morrison and Gettelman 2008) with a suite of compatible cloud macro physics schemes, which handle cloud fraction, horizontal and vertical overlapping and conversion from water vapor to cloud condensate (Neale 2010); and (3) a radiative transfer model for GCM (RRTMG) package for calculating the radiation (Mlawer et al. 1997).

Forced by monthly historical sea surface temperatures (SSTs), a long-term experiment, from January 1979 to December 2009, was conducted at T266 horizontal resolution $\left(0.45^{\circ} \times 0.45^{\circ}\right)$. Using the monthly output from 30 years (1980-2009), the rainfall and large-scale circulation patterns in the Northern Hemisphere during mid-summer (JulyAugust; JA) were investigated.

Monthly temperature and circulation reanalysis data utilized were from the US National Centers for Environmental Prediction/National Center for Atmospheric Research (NCEP/NCAR) (Kalnay et al. 1996). The data set had a horizontal resolution of $2.5^{\circ} \times 2.5^{\circ}$ and contained 17 vertical levels. The precipitation data used comprised daily rain gauge records from 754 stations across China during 1980-2009; these data were archived and quality controlled by the National Meteorological Information Center of the China Meteorological Administration.

\section{Results}

\subsection{Simulation of climatological precipitation and circulation}

Precipitation is a critical indicator of monsoon activities and its simulation is a result of the combined action of dynamical and physical progress in the numerical model. We first investigated the performance of the model in simulating the climatological precipitation and upper/lower-tropospheric circulation patterns during JA in East Asia. The observations and model results are provided in Fig. 1a, b, respectively.

For the study period, observations (Fig. 1a) show that the main rain belt in China is located around the Yangtze River Valley and the regions south of $25^{\circ} \mathrm{N}$. Less rainfall appears north of $35^{\circ} \mathrm{N}$ in the observations, while northern and northeastern China still have several strong rainfall regions. The model (Fig. 1b) fails to reproduce the rain belt south of $35^{\circ}$ $\mathrm{N}$; the whole spatial distribution of rainfall is northward, compared to the observations, with the main rain belt being at about $37.5^{\circ}-40^{\circ} \mathrm{N}$. As such, the precipitation simulated to the south of $35^{\circ} \mathrm{N}$ is weaker than the observations. For example, in the regions south of the middle and lower reaches of the Yangtze River Valley, precipitation reaches $7 \mathrm{~mm}^{\text {day }}{ }^{-1}$ in the observations but is only $4 \mathrm{~mm} \mathrm{day}^{-1}$ in the model. Meanwhile, the high-resolution model performs well in simulating the precipitation in the complex topographic area of southwestern China, where the precipitation levels in the center of the peak are similar to those in the observations.

In the upper troposphere, observations (Fig. 1a) show that the maximum center of the $200 \mathrm{hPa}$ westerly jet is located around $40^{\circ} \mathrm{N}$ and the speeds of the westerlies exceed $25 \mathrm{~m} \mathrm{~s}^{-1}$ in the regions west of $125^{\circ} \mathrm{E}$. In the model (Fig. 1b), the maximum center of the westerly jet axis at $200 \mathrm{hPa}$ is located around $45^{\circ} \mathrm{N}$ and the regions where the westerlies are stronger than $25 \mathrm{~m} \mathrm{~s}^{-1}$ are centered to the west of $105^{\circ} \mathrm{E}$. The maximum center of the westerly jet in the model is also further north than that in the observations.

In the lower troposphere, the model reproduces the southerlies in eastern China at $850 \mathrm{hPa}$, but they are located further north and are stronger than the observations, which is consistent with the differences in the rain belt distribution, as described above. In addition, the shear point of the mid-lower troposphere easterlies and westerlies is at about $30^{\circ} \mathrm{N}$ in the observations but is $5^{\circ} \mathrm{N}$ further north than this in the model.

\subsection{Changes in eastern China precipitation}

The rain gauge records show that precipitation in eastern China experienced distinct interdecadal changes at beginning of the twenty-first century (Zhao et al. 2015); the precipitation anomalies change from negative to positive in the Huaihe River Valley (north of $32^{\circ} \mathrm{N}$ ), and the opposite occurs in the regions south of the mid-lower reaches of the Yangtze River Valley (south of $32^{\circ} \mathrm{N}$ ). In the simulation results, the precipitation anomalies change from positive to negative in the regions between $30^{\circ}-40^{\circ} \mathrm{N}$ and $110^{\circ}-120^{\circ}$ E. Compared to the observed decrease in precipitation south of the mid-lower reaches of the Yangtze River Valley, the regions simulated to have decreased precipitation are located further north (figure not shown).

To investigate the large circulation changes that correspond to the changes in precipitation, we selected two critical regions in eastern China from the observations and model results, respectively (observation: $25^{\circ}-30^{\circ} \mathrm{N}, 110^{\circ}-120^{\circ} \mathrm{E}$; model: $30^{\circ}-$ $40^{\circ} \mathrm{N}, 110^{\circ}-120^{\circ} \mathrm{E}$ ), which both experience distinct precipitation decreases. We extracted the regional averaged time series of precipitation for these two critical regions (Fig. 2). Then, we chose the years in which the precipitation levels were more (less) than $+0.75(-0.75)$ standard deviation to represent the wetter (drier) years in the critical regions. Finally, we evaluated the performance of the model in simulating the large-scale circulation changes corresponding to the anomalous precipitation years, using the composite analysis method.

In the observations, there are 6 years each of more and less rainfall than usual; the wetter years are 1980, 1993, 1996, 
(a)

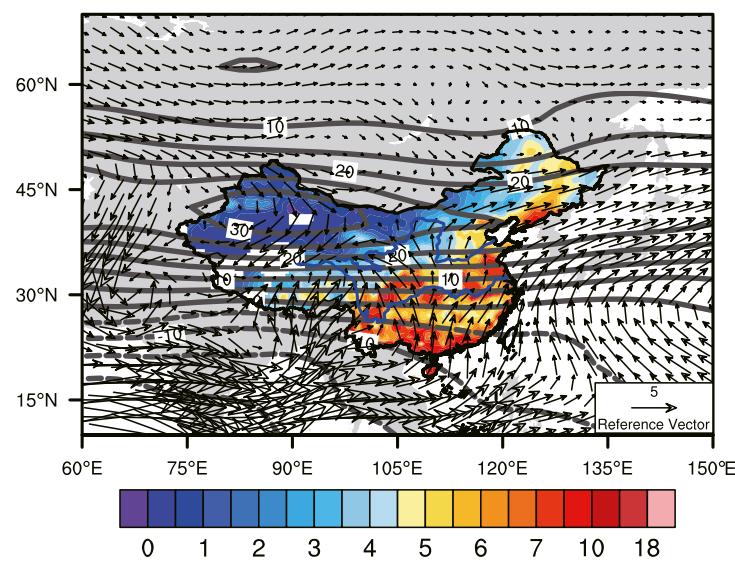

Fig. 1 Mid-summer (July-August) climatological mean (1980-2009) precipitation (shading, mm day ${ }^{-1}$ ), zonal wind at $200 \mathrm{hPa}$ (contours, $\mathrm{m} \mathrm{s}^{-1}$ ), and horizontal wind fields at $850 \mathrm{hPa}$ (vectors, $\mathrm{m} \mathrm{s}^{-1}$ ) derived

1997, 1999, and 2002 and the drier years are 1981, 1986, 1990, 1991, 2003, and 2005. The model simulates 7 years each of more and less rainfall than usual; the wetter years are 1980, 1981, 1990, 1993, 1996, 2002, and 2008 and the drier years are 1984, 1988, 1999, 2000, 2003, 2005, and 2007. The differences in mean precipitation between the drier years and the wetter years represent the change features in the selected critical regions, when there is less rainfall. Figure 3 shows the precipitation distribution of this composite analysis. In both the observations and model results, there are similar and distinct precipitation decreases and slight increases in the north of the selected critical regions (black boxes), although these are not significant. However, the precipitation amplitudes are weaker in the model than in the observations.

\subsection{3-D large-scale circulation changes in East Asia}

As indicated by Yu et al. (2004), the interdecadal changes of precipitation over eastern China are closely related to the coherent three dimensional large-scale circulation changes,

(a)

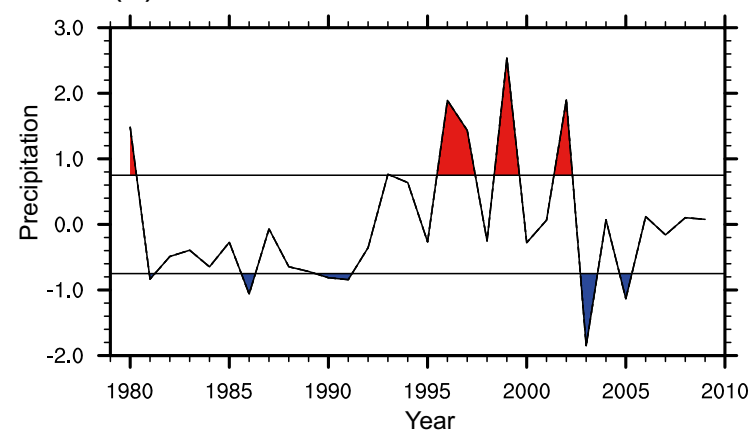

Fig. 2 Regional averaged and standardized precipitation time series of a station rainfall records (averaged over $25^{\circ}-30^{\circ} \mathrm{N}, 110^{\circ}-120^{\circ} \mathrm{E}$ ) and $\mathbf{b}$ NCAR CAM5 simulation results (averaged over $30^{\circ}-40^{\circ} \mathrm{N}, 110^{\circ}-120^{\circ}$ (b)

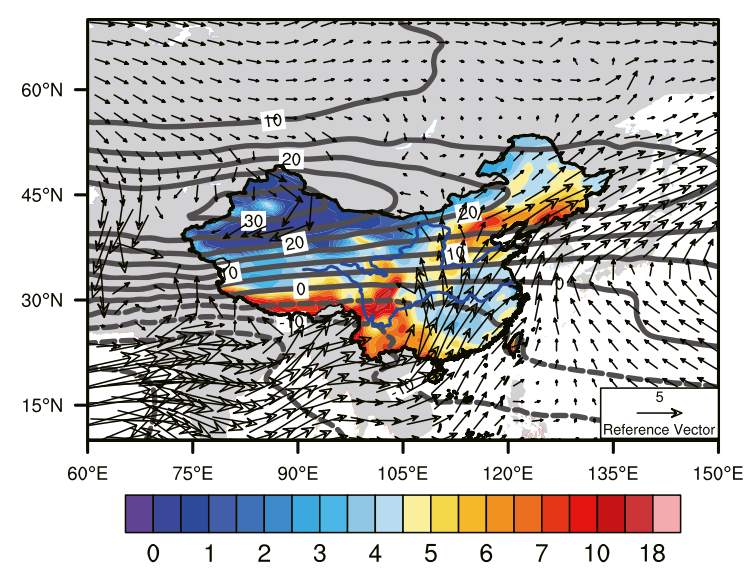

from a station rainfall records and NCEP circulation reanalysis and $\mathbf{b}$ NCAR CAM5 simulation results

characterized by the upper-tropospheric temperature changes. Figure 4 presents the results of the upper-tropospheric (500 $200 \mathrm{hPa}$ ) temperature differences between the unusually wet and dry rainfall years during JA. The model simulates the strongest warm center in the Northern Hemisphere to be over East Asia, corresponding to the observations. The warm center is located over Mongolia $\left(35^{\circ}-50^{\circ} \mathrm{N}, 100^{\circ}-120^{\circ} \mathrm{E}\right)$, where the simulated temperature rises more than $1^{\circ} \mathrm{C}$, a little weaker than the observations (in which it increases by about $1.2^{\circ} \mathrm{C}$ ).

The geopotential height changes in accordance with uppertropospheric temperatures over East Asia. In Fig. 5, the meridional-averaged cross sections $\left(100^{\circ}-120^{\circ} \mathrm{E}\right)$ of differences in temperature and geopotential height between the wetter and driers than usual years are presented. In the observations (Fig. 5a), there is a downward stretching warm center in the mid- to high-latitude area of East Asia $\left(25^{\circ}-50^{\circ} \mathrm{N}\right)$. In the East Asian region between $25^{\circ}$ and $37.5^{\circ} \mathrm{N}$, the warm center in the upper troposphere is at $300-200 \mathrm{hPa}$. Corresponding with this upper-tropospheric temperature rise in East Asia, the geopotential height significantly increases above the warm

(b)

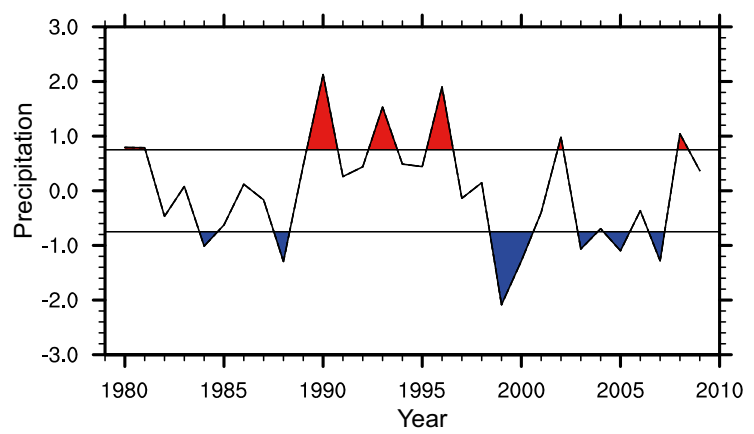

E). In the red (blue) marked years, the precipitation levels are more (less) than $+0.75(-0.75)$ standard deviation 
Fig. 3 The difference in mean precipitation, during JulyAugust, between the drier and wetter years (drier minus wetter; $\mathrm{mm} \mathrm{day}^{-1}$ ) derived from a station rainfall records and $\mathbf{b}$ NCAR CAM5 simulation results. The black boxes indicate the critical regions in the observation and model. The black slashes indicate where the changes are statistically significant $(P<0.05)$ (a)

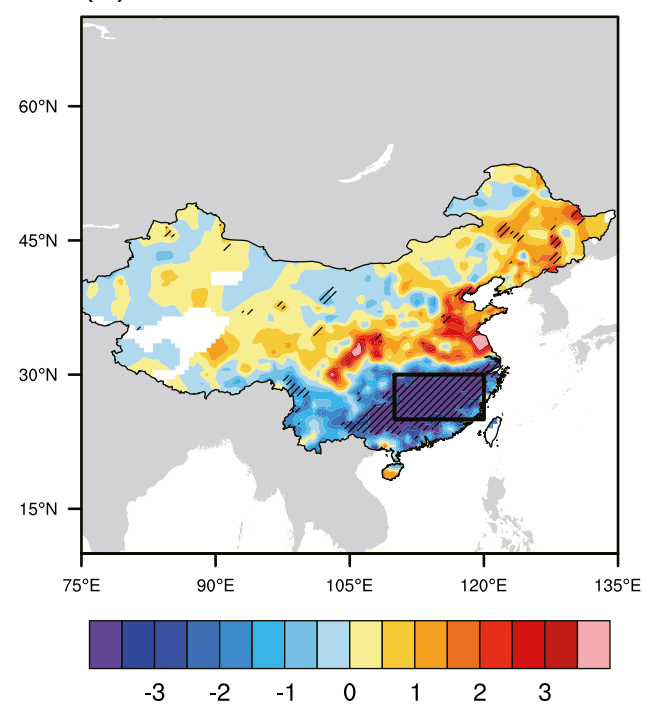

(b)

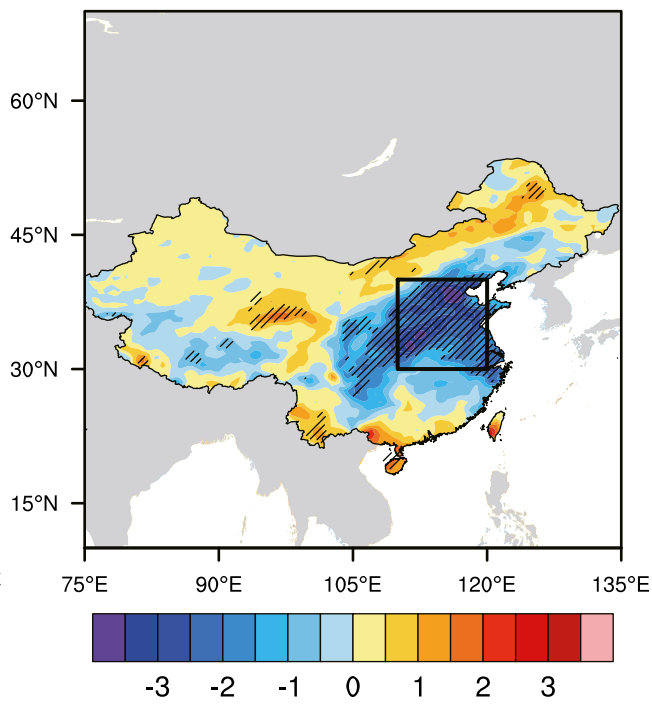

center. There is a southward shift in the warm center, where it spans from the upper to lower troposphere and presents a baroclinic structure in the troposphere. The geopotential height observations present the same spatial structure; divided at $32^{\circ} \mathrm{N}$, the geopotential height rises to the south and declines to the north, as it is affected by the cold center at lower troposphere.

The spatial structure of the temperature increase in East Asia is reproduced well by the model (Fig. 5b). The baroclinic structure of the temperature rise is simulated, extending from the upper troposphere down to the surface. The strongest warm center in East Asia appears between 500 and $200 \mathrm{hPa}$, at about $35^{\circ}-50^{\circ} \mathrm{N}$, with the peak at $300 \mathrm{hPa}$. The location of the upper-tropospheric warm center is further north, compared to the observations, and its amplitude is weaker (rises of about $1{ }^{\circ} \mathrm{C}$ are simulated in the model, while there are $1.2^{\circ} \mathrm{C}$ increases in the observations). Above the warm center, the simulated geopotential height correspondingly rises; the $200 \mathrm{hPa}$ geopotential height rises above $30 \mathrm{~m}$. A remarkable

(a)

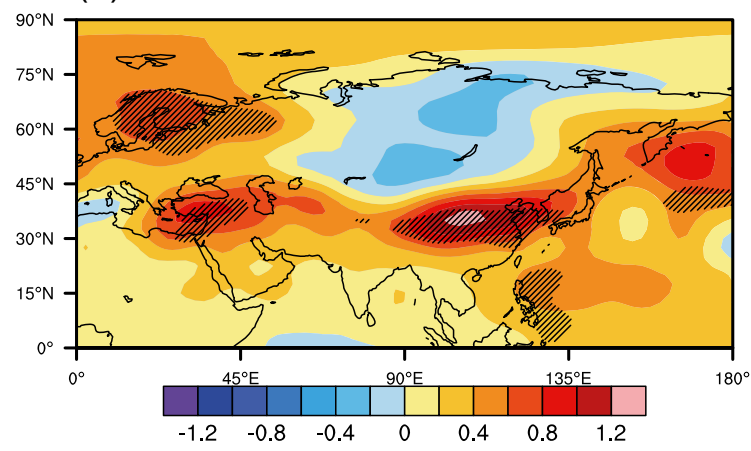

Fig. 4 The difference in mean upper-tropospheric (500-200 hPa) temperature $(\mathrm{K})$, during July-August, between the drier and wetter years (drier minus wetter), derived from a NCEP reanalysis and $\mathbf{b}$ NCAR geopotential height gradient is simulated to the north of the peak center, around $52^{\circ} \mathrm{N}$. The baroclinic structure of the temperature and the geopotential height increases, and their configurations are reproduced well by the model.

Figure 6 presents the zonal $\left(30^{\circ}-40^{\circ} \mathrm{N}\right.$, observations; $35^{\circ}-$ $50^{\circ} \mathrm{N}$, model) averaged cross sections of the differences in temperature and geopotential height between the wetter and drier than usual years. The strongest warm center in the observations is located at $300-200 \mathrm{hPa}$, between $90^{\circ}$ and $120^{\circ} \mathrm{E}$, with increases of more than $1^{\circ} \mathrm{C}$ (Fig. 6a). The geopotential height change reaches a maximum at $200 \mathrm{hPa}$, with the center to the east of the warm center, around $110^{\circ} \mathrm{E}$. The temperature increase extends eastward from the upper to lower troposphere, producing a baroclinic structure; and the geopotential increases similarly.

The model reproduces a realistic spatial structure and configuration of the changes in temperature and corresponding geopotential height (Fig. 6b); however, the simulated amplitudes of both parameters are weaker. The regions showing

(b)

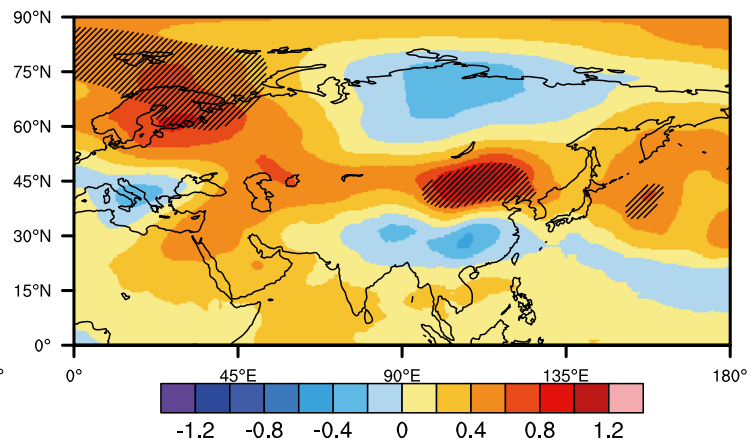

CAM5 simulation results. The black slashes indicate where the changes are statistically significant $(P<0.05)$ 
Fig. 5 Latitude-height cross section averaged $\left(100^{\circ}-120^{\circ} \mathrm{E}\right)$, July-August, mean differences in temperature (shading, $\mathrm{K}$ ) and geopotential height (contours; gpm in observation and $\mathrm{m}$ in model) between the drier and wetter years, derived from the a NCEP reanalysis and $\mathbf{b}$ NCAR CAM5 simulation results. The black slashes indicate where the changes are statistically significant $(P<0.05)$ (a)

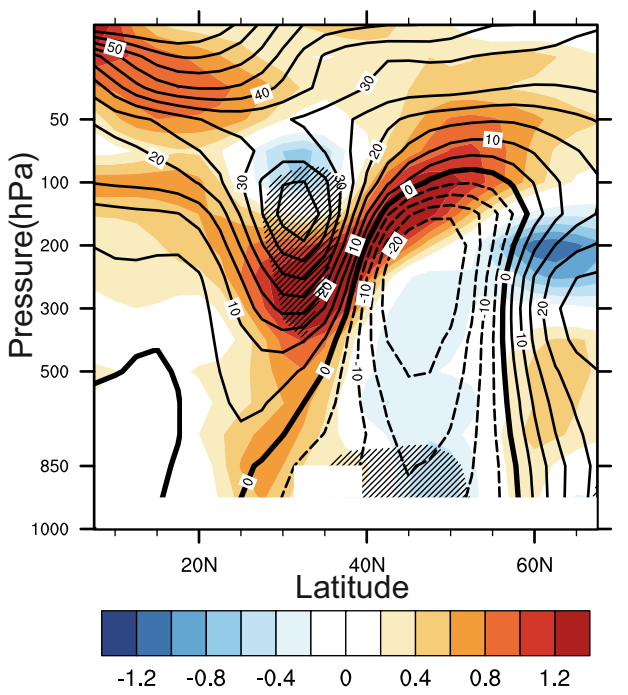

(b)

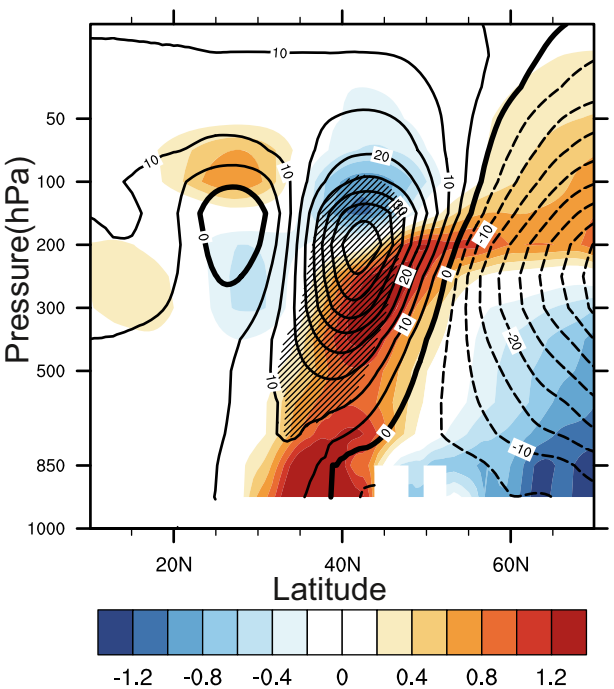

temperature rises over $0.8^{\circ} \mathrm{C}$ are only concentrated between $100^{\circ}$ and $110^{\circ} \mathrm{E}$, and the warm center is lower than in the observations. The strongest warm center is located at $300 \mathrm{hPa}$. The spatial structure of the temperature change is similar to the observations; it stretches eastward from the upper to lower troposphere, and the surface warm center occurs between $110^{\circ}$ and $120^{\circ} \mathrm{E}$. Corresponding to the temperature increase in the upper troposphere, the geopotential height significantly rises above the warm center, over $28 \mathrm{~m}$, with a similar baroclinic structure. Similar to the temperature change, the amplitude of the geopotential height increase is weaker in the model.

Based on the geostrophic adaption theory, wind fields adapt to pressure fields in large-scale motions. Corresponding to the variations of the upper-tropospheric temperature and geopotential height, the coherent 3-D circulation in East Asia experiences significant changes. Figure 7 shows the differences in circulation between the wetter and drier than usual years, in the upper (a) and lower (b) troposphere, according to observations. The model precisely reproduces the representative changes in the 3-D large-scale circulation patterns (Fig. 7c, d).

In the upper troposphere, along with the change in geopotential height, an anticyclone is simulated above the warm center at $35^{\circ}-50^{\circ} \mathrm{N}$ and $100^{\circ}-130^{\circ} \mathrm{E}$ (Fig. 7c). It is similar to the observed anticyclone (Fig. 7a), but a bit further north. Divided at $40^{\circ} \mathrm{N}$, the $200 \mathrm{hPa}$ zonal winds show anomalous westerlies to the north and easterlies to the south (Fig. 7a). There is a strong gradient toward the north in the geopotential height around $50^{\circ} \mathrm{N}$ (Fig. 5b); based on the geostrophic balance, the westerlies increase most at the regions
Fig. 6 As for Fig. 5, but for the longitude-height cross section, averaged over a $30^{\circ}-45^{\circ} \mathrm{N}$ and derived from the NCEP reanalysis and $\mathbf{b} 35^{\circ}-50^{\circ} \mathrm{N}$ and derived from the NCAR CAM5 simulation results (a)

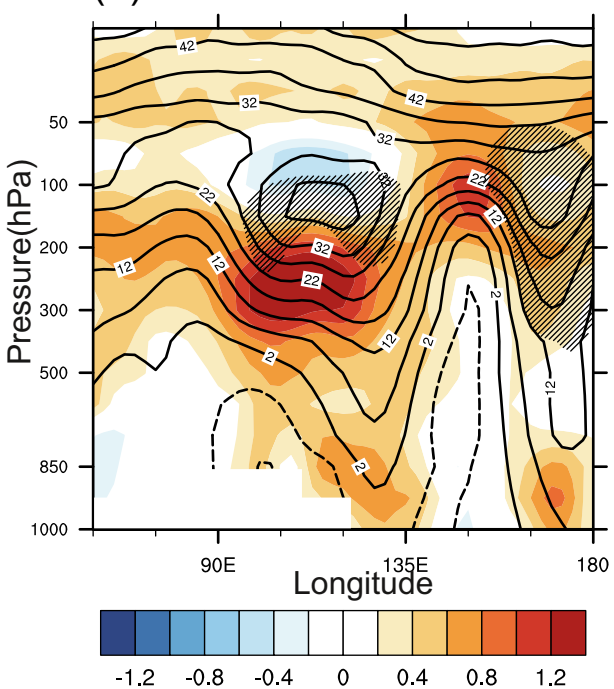

(b)

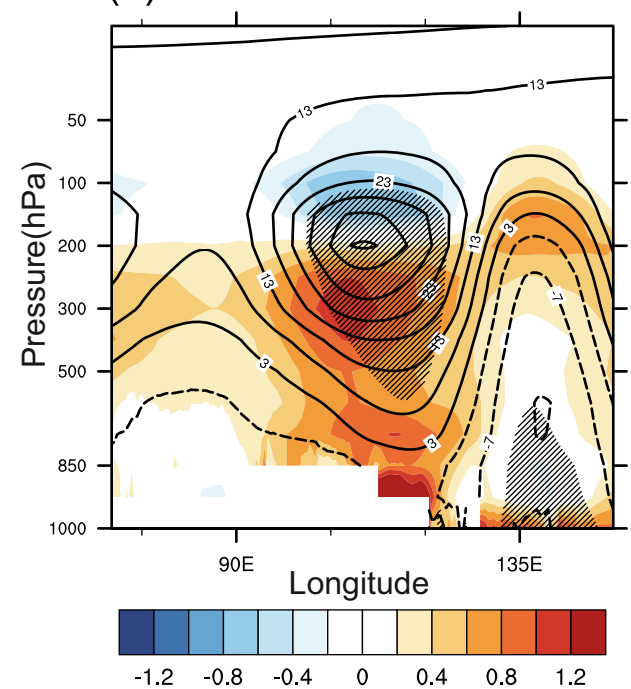


Fig. 7 The drier minus the wetter years' (July-August) means of the geopotential height (shading, gpm) and wind fields (vectors, $\mathrm{m} \mathrm{s}^{-1}$ ), derived from the $\mathbf{a}, \mathbf{b}$ NCEP reanalysis and $\mathbf{c}, \mathbf{d}$ NCAR CAM5 simulation results at $\mathbf{a}, \mathbf{c}$ $200 \mathrm{hPa}$ and $\mathbf{b}, \mathbf{d} 850 \mathrm{hPa}$. The black slashes and red vectors indicate where the changes are statistically significant $(P<0.05)$ (a)

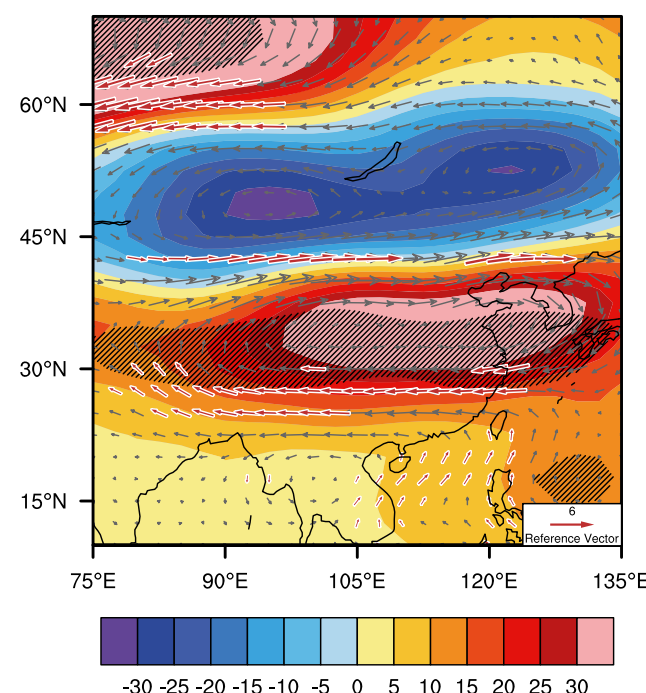

(c)

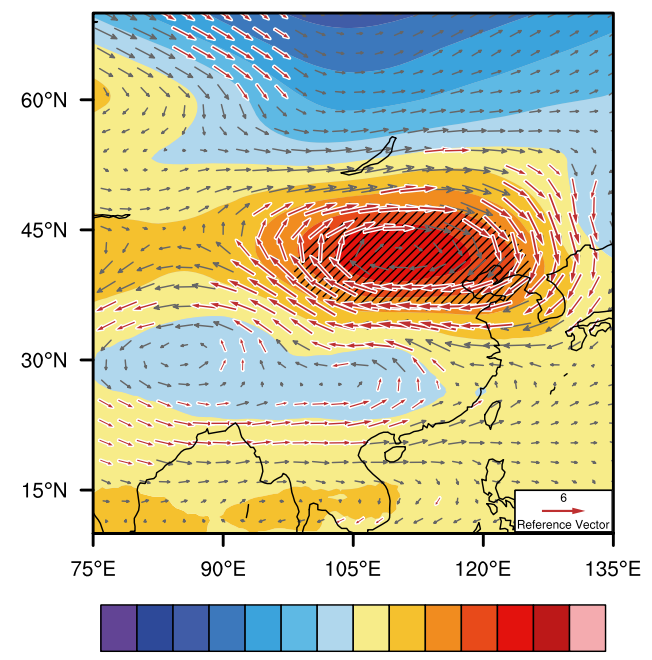

$-60-50-40-30-20-10 \quad 0 \quad 10 \quad 20 \quad 30 \quad 40 \quad 50 \quad 60$ (b)

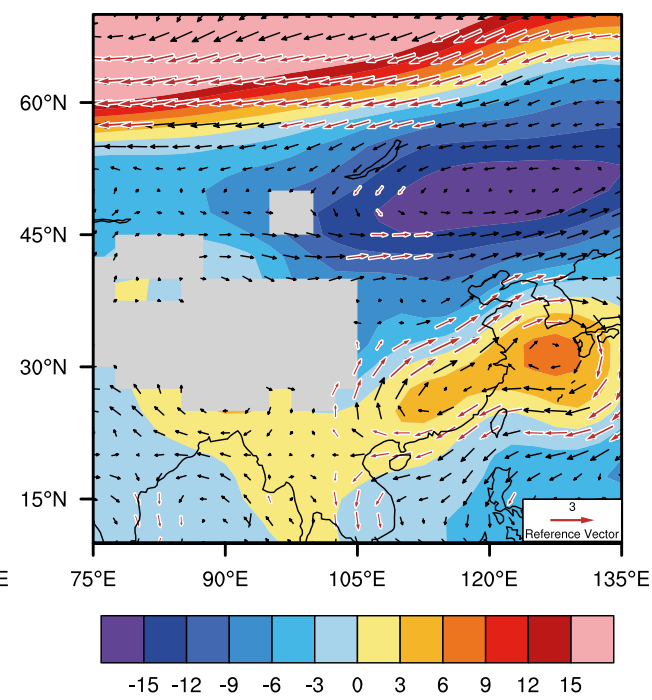

(d)

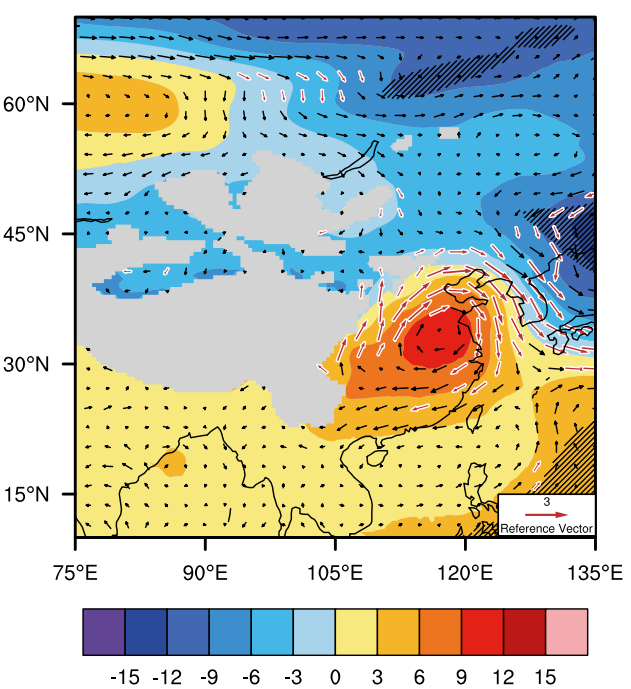

with the greatest temperature gradient. Corresponding to the geopotential height gradient around $50^{\circ} \mathrm{N}$, the $200 \mathrm{hPa}$ westerlies increase significantly between $40^{\circ}$ and $50^{\circ} \mathrm{N}$.

The strong anomalous westerlies north of $40^{\circ} \mathrm{N}$ move the subtropical westerly jet northward in the drier years, compared to the wetter years. Between $100^{\circ}$ and $130^{\circ} \mathrm{E}$, the westerly jet stream moves about $3^{\circ}$ northward (figure not shown). Kuang and Zhang (2006) and Kwon et al. (2005) suggested that the East Asian summer rainfall is closely related to the location and amplitude of the subtropical westerly jet. When the jet moves northward, the region of convergence, leading to upward air movement, shifts northward, resulting in less rain in the southern regions. Both in the observations and model results, corresponding with the jet moving northward, there are significant anomalous downdrafts in the selected critical regions (figure not shown), which result in a decrease in rainfall.
Corresponding with the lower-tropospheric temperature increase (Fig. 5b), at the warm center, the model reproduces the geopotential height rising over $6 \mathrm{~m}\left(25^{\circ}-40^{\circ} \mathrm{N}, 105^{\circ}-135^{\circ} \mathrm{E}\right.$; Fig. 7d); this is similar to the observations (Fig. 7b), except that the observations are weaker in amplitude. In the observations and simulation results, anomalous anticyclones appear in regions where the geopotential height increases, with anomalous southerlies to their west, between $30^{\circ}$ and $40^{\circ} \mathrm{N}$ in the observations and $37^{\circ}-50^{\circ} \mathrm{N}$ in the simulation results. Numerous studies have chosen the southerlies in this region as an index of the EASM ( $\mathrm{Li}$ and Zeng 2002; Wu and Wang 2002), where stronger southerlies indicate a stronger EASM. The model reproduces the strengthening of the EASM in this region, as shown in the observations. The stronger EASM leads to the northward shift of the monsoon rain belt, which results in less rainfall in the critical regions. 
Figure 8 shows the differences in the vertically integrated water vapor flux divergence and transportation between the wetter and drier years. The vertically integrated vapor flux $\boldsymbol{Q}$ can be written as

$\boldsymbol{Q}=g^{-1} \int_{p s}^{p t} q \boldsymbol{V} d p$

where $g$ is the acceleration due to gravity, $q$ the specific humidity, and the vector $\boldsymbol{V}$ represents the total wind. $p_{s}$ is the surface pressure and $p_{t}$ the pressure at the top of the atmosphere. The vapor flux divergence can be calculated as

$\boldsymbol{Q}_{\text {div }}=g^{-1} \int_{p s}^{p t} q \nabla \boldsymbol{V} d p$

and here, $p_{t}=300 \mathrm{hPa}$ and $p_{s}=1000 \mathrm{hPa}$.

In the observations (Fig. 8a), water vapor divergence occurs in regions south of the Yangtze River Valley and its convergence occurs in northern China and the Huaihe River Valley. These convergence and divergence regions are divided at $32^{\circ} \mathrm{N}$. A similar distribution of water vapor convergence and divergence is simulated by the model (Fig. 8b). Divided at $40^{\circ} \mathrm{N}$, significant divergence of water vapor occurs around $30^{\circ}-40^{\circ} \mathrm{N}$ and $105^{\circ}-120^{\circ} \mathrm{E}$, with convergence regions to the north of the area; thus, the arid/moist configuration is located slightly northward of that observed. Focusing on the transportation of the water vapor, anomalous southerlies bring a large quantity of water vapor to the northern regions, causing a lack of water vapor supply in the critical regions and an excess of water vapor in the northern regions. This water vapor configuration, corresponding to the coherent large-circulation changes, is simulated well (Fig. 8b).

Above, we have comprehensively analyzed the performance of the model in simulating coherent changes of the 3-
D structure, characterized by upper-tropospheric warming, including the upper-level jet and the lower-level EASM in drier years in East Asia. We further analyzed the relationship between the key circulation elements and the upper-tropospheric warming; we used the standardized time series, averaged from the regions with the most significant temperature increases, as the upper-tropospheric temperature index (UTI). Table 1 gives the correlation coefficients between the UTI and other circulation and rainfall indexes in the observations and model results. There are good relationships between the model results for the UTI and other indexes relating to the 3-D structure, as for the observations. The upper-tropospheric temperature over East Asia is positively correlated with the $200 \mathrm{hPa}$ westerlies and lower-tropospheric southerlies and negatively correlated with precipitation in the critical regions. The correlation coefficients between the UTI and $200 \mathrm{hPa}$ westerlies are 0.45 in the model results and 0.73 in observations; these are both higher than other correlations. The correlation coefficients of the lower-tropospheric circulation patterns with the UTI are not as good as for the upper troposphere, which might be due to the complicated influences of many factors, such as topography. Except for the relationship with precipitation, the correlation coefficients in the model are weaker than in the observations, but they are still significant.

The correlation analysis between the upper-tropospheric temperature and the other circulation indexes further confirms the close relationship in the coherent 3-D structure of the model simulation. On the one hand, the model faithfully reproduces the upper-tropospheric warming, the corresponding appearance of the anticyclone and the northward shift of the subtropical westerly jet. On the other hand, the lowertropospheric warm center is accompanied with an anticyclone in the lower troposphere, and the EASM is strengthened correspondingly. The northward shift of the upper-tropospheric
Fig. 8 The drier years minus the wetter years' (July-August) means of the vertically integrated (1000-300 hPa) water vapor flux divergence (shading,

$\left.10^{4} \mathrm{~kg} \mathrm{hPa}^{-1} \mathrm{~m}^{-2} \mathrm{~s}^{-1}\right)$ and water vapor flux (vectors, $\mathrm{m} \mathrm{s}^{-1}$ ), derived from the a NCEP reanalysis and b NCAR CAM5 simulation results. The black slashes and red vectors indicate where the change is statistically significant $(P<0.05)$. All of the figures are created using The NCAR Command Language (http://www.ncl.ucar.edu/) (a)

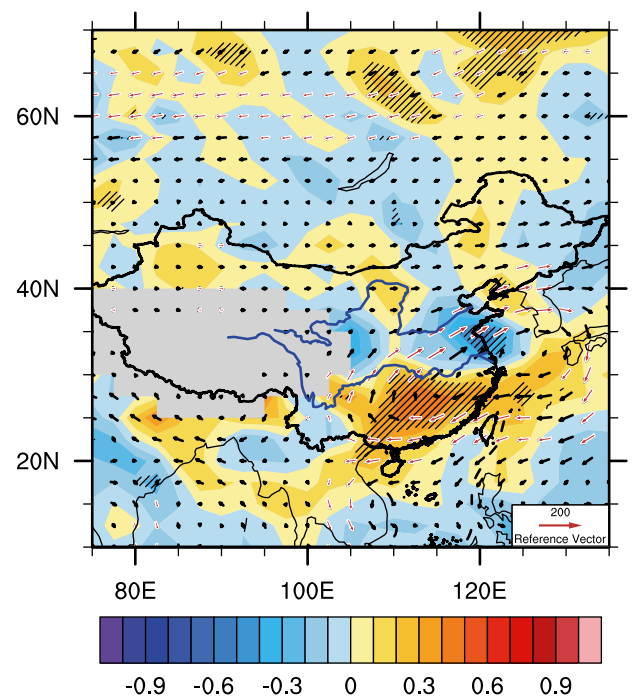

(b)

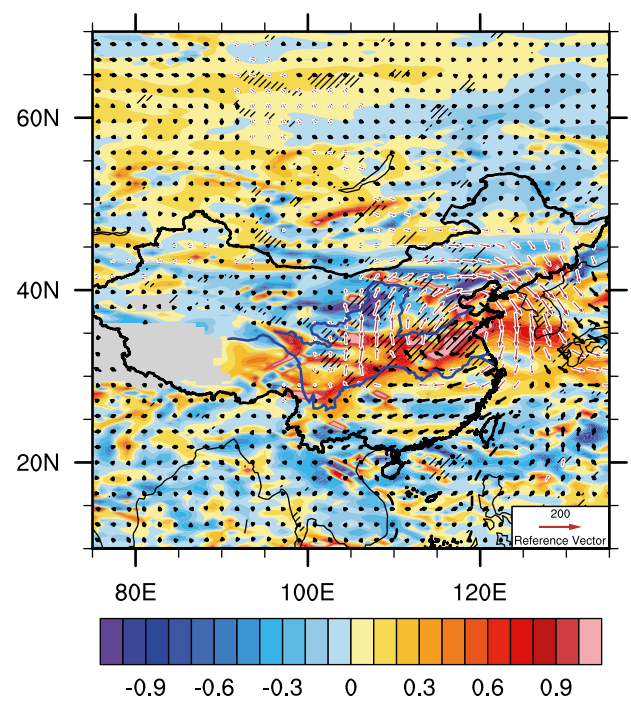


Table 1 Correlation coefficients between the UTI and other circulation and rainfall indexes in the observations and model results

\begin{tabular}{|c|c|c|c|c|c|}
\hline \multicolumn{3}{|l|}{ Observations } & \multicolumn{3}{|l|}{ Model simulation } \\
\hline $\begin{array}{c}\mathrm{T}_{300 \mathrm{hPa}}\left(30^{\circ}-40^{\circ} \mathrm{N}\right. \\
\left.100^{\circ}-120^{\circ} \mathrm{E}\right)\end{array}$ & & & $\begin{array}{c}\mathrm{T}_{300 \mathrm{hPa}}\left(40^{\circ}-50^{\circ} \mathrm{N}\right. \\
\left.100^{\circ}-120^{\circ} \mathrm{E}\right)\end{array}$ & & \\
\hline $\begin{array}{l}\mathrm{U}_{200 \mathrm{hPa}}\left(40^{\circ}-50^{\circ} \mathrm{N}\right. \\
\left.90^{\circ}-120^{\circ} \mathrm{E}\right)\end{array}$ & $\begin{array}{c}\mathrm{V}_{850 \mathrm{hPa}}\left(25^{\circ}-30^{\circ} \mathrm{N}\right. \\
\left.100^{\circ}-120^{\circ} \mathrm{E}\right)\end{array}$ & $\begin{array}{c}\operatorname{PRE}\left(25^{\circ}-30^{\circ} \mathrm{N},\right. \\
\left.110^{\circ}-120^{\circ} \mathrm{E}\right)\end{array}$ & $\begin{array}{c}\mathrm{U}_{200 \mathrm{hPa}}\left(45^{\circ}-55^{\circ} \mathrm{N},\right. \\
\left.90^{\circ}-120^{\circ} \mathrm{E}\right)\end{array}$ & $\begin{array}{c}\mathrm{V}_{850 \mathrm{hPa}}\left(30^{\circ}-40^{\circ} \mathrm{N}\right. \\
\left.100^{\circ}-120^{\circ} \mathrm{E}\right)\end{array}$ & $\begin{array}{c}\operatorname{PRE}\left(30^{\circ}-40^{\circ} \mathrm{N}\right. \\
\left.110^{\circ}-120^{\circ} \mathrm{E}\right)\end{array}$ \\
\hline 0.73 & 0.40 & -0.42 & 0.45 & 0.28 & -0.44 \\
\hline
\end{tabular}

Bold values are statistically significant $(P<0.05)$

jet and the strengthening of the lower-level EASM are two critical factors that lead to less rainfall in the critical regions and both show similar variations in the observations and model simulation.

\section{Conclusions and discussion}

In this paper, we comprehensively assessed the performance of the high-resolution climate model NCAR CAM5, forced with historical SSTs, in simulating the changes of precipitation and the corresponding 3-D circulation structure during JA, across East Asia. The results show that although the model has biases in simulating the precipitation, it successfully captures coherent changes of the precipitation and the 3-D circulation structure.

In summary, corresponding to a decrease in regional precipitation over eastern China, in mid-summer, the large-scale circulation in East Asia shows coherent variations:

1. The upper-tropospheric temperature rises significantly across northern China and Mongolia, with a baroclinic structure extending down to the surface. Corresponding to the upper-tropospheric warming, an anomalous anticyclone appears above the warm center and anomalous westerlies occur to the north of it; these lead to the subtropical westerly jet moving northward.

2. At lower troposphere, corresponding to the surface warming, an anticyclone appears, with anomalous southerlies to the east of it. The anomalous southerlies strengthen the EASM and bring more water vapor to the northern regions.

3. The upper-tropospheric temperature rise is closely related to the circulation changes. The upper-tropospheric temperature is highly correlated with the $200 \mathrm{hPa}$ westerlies and the precipitation in the critical regions. However, the relationship with the $850 \mathrm{hPa}$ southerlies is a little bit weaker, which might be due to the complex influences of many lower-tropospheric factors, like topography.

The NCAR CAM5 climate model still exhibits certain biases; for example, the location of the upper-tropospheric zonal winds, lower-tropospheric circulation, and rain belt are all slightly north of observations. In addition, the precipitation levels in eastern China are weaker. These outcomes are consistent with previous studies; even the advanced general circulation models still have large biases when used to simulate the East Asian climate (Chen et al. 2010; Song et al. 2014; Sperber et al. 2013; Turner et al. 2008). Chen and Frauenfeld (2014) indicated that the CMIP5 overestimates the magnitude of seasonal and annual precipitation in most regions of China. Zhou et al. (2009b) analyzed multimodel ensemble simulation results and found that over the extratropical western North Pacific and South China Sea, the MME fails to demonstrate any skill in summer. This might be due to the lack of consideration in air-sea interaction in atmospheric general circulation model. However, the analysis in this paper has also demonstrated that, despite the model biases, NCAR CAM5 is still relevant for climate variation research in East Asia. The model reproduces the coherent structure of the large-circulation changes corresponding to rainfall changes in East Asia well. Therefore, the model has the potential to be applied to allow interpretation of the mechanisms that cause climate change in East Asia. However, while carrying out such numerical experiments, it is necessary to consider the system biases that may be influenced by the model itself.

This experiment was carried out at a high horizontal resolution. Research has shown that medium- and low-resolution models have significant deficiencies, in terms of depicting the EASM rain belt's location, seasonal shifts, and interannual variations (Chen et al. 2010; Lin et al. 2008; Zhou and Li 2002; Zhou et al. 2010); in particular, they create a false heavy rainfall center over the eastern edge of the Tibetan Plateau (Yu et al. 2000). The high-resolution model has shown significant improvements in its ability to simulate East Asian precipitation, especially orographic precipitation, compared to previous models (Gent et al. 2010; Kusunoki et al. 2006; Li et al. 2015). While the results show that the high-resolution model improves the precipitation simulation (Fig. 1), compared to the low-resolution model (figure not shown), there are no significant improvements at reproducing the precipitation in the eastern China and Plain areas. This indicates that there remain some biases in the model itself, despite the use of a high resolution (Lau and Ploshay 2009; Yuan et al. 2013). 
In this work, the composite analysis is used to reveal the coherent structure corresponding to the rainfall changes in NCAR CAM5 high-resolution simulations, but the model performance on the interdecadal change mentioned by Zhao et al. (2015) including the upper-tropospheric temperature trend change still needs further study. Besides, the physical and dynamical mechanisms behind the interannual and interdecadal climate change at the beginning of the twentyfirst century remain elusive, especially the mechanisms driving the upper-tropospheric temperature changes. Probable factors include atmospheric oscillations and interactions between the stratosphere and troposphere (Xin et al. 2006; Yu et al. 2004). Based on this paper, further attribution research of interannual and interdecadal changes in the East Asian climate using numerical experiments is warranted.

Acknowledgments This work was jointly supported by the Outstanding Tutors for doctoral dissertations of S\&T project in Beijing under Grant 20138005801; the National Natural Science Foundation of China under Grant Nos. 41221064 and 41375004; and the Basic Scientific Research and Operation Foundation of CAMS under Grant 2014R013.

Open Access This article is distributed under the terms of the Creative Commons Attribution 4.0 International License (http:// creativecommons.org/licenses/by/4.0/), which permits unrestricted use, distribution, and reproduction in any medium, provided you give appropriate credit to the original author(s) and the source, provide a link to the Creative Commons license, and indicate if changes were made.

\section{References}

Baldwin MP, Thompson DW, Shuckburgh EF, Norton WA, Gillett NP (2003) Weather from the stratosphere. Science 301:317-319

Bretherton CS, Park S (2008) A new bulk shallow-cumulus model and implications for penetrative entrainment feedback on updraft buoyancy. J Atmos Sci 65:2174-2193

Chen H (2014) Validation of the CMIP5 climate models in simulating decadal variations of summer rainfall in eastern China (in Chinese) climatic and. Environ Res 6:773-786

Chen L, Frauenfeld OW (2014) A comprehensive evaluation of precipitation simulations over China based on CMIP5 multimodel ensemble projections. J Geophys Res 119:5767-5786

Chen T, Wang S, Huang W, Yen M, Chen T, Yen M (2004) Variation of the East Asian summer monsoon rainfall. J Clim 17:744-762

Chen H, Zhou T, Neale RB, Wu X, Zhang GJ (2010) Performance of the new NCAR CAM3.5 in East Asian summer monsoon simulations: sensitivity to modifications of the convection scheme. J Clim 23 : 3657-3675

Chen H, Yu R, Li J, Xin X, Wang Z, Wu T (2012) The coherent interdecadal changes of East Asia climate in mid-summer simulated by BCC_AGCM 2.0. 1. Clim Dyn 39:155-163

Dai A (2010) Drought under global warming: a review. Wiley Interdisciplinary Reviews Climate Change 2:45-65

Ding Y (1992) Summer monsoon rainfalls in China. J Meteorol Soc Jpn 70:373-396

Ding Y, Chan JC (2005) The East Asian summer monsoon: an overview. Meteorog Atmos Phys 89:117-142
Ding Y, Ren G, Zhao Z, Ying XU, Luo Y, Qiaoping LI, Zhang J (2007) Detection, causes and projection of climate change over China: an overview of recent progress advances in atmospheric. Sciences 06: 954-971

Ding Y, Wang Z, Sun Y (2008) Inter-decadal variation of the summer precipitation in East China and its association with decreasing Asian summer monsoon. Part I: observed evidences. Int J Climatol 28: 1139-1161

Ding Y, Liu Y, Sun Y, Song Y (2010) Weakening of the Asian summer monsoon and its impact on the precipitation pattern in China. Water Resour Dev 26:423-439

Du Y, Zhang Y, Xie Z (2009) Location variation of the East Asia subtropical westerly jet and its effect on the summer precipitation anomaly over eastern China (in Chinese). Chinese Journal of Atmospheric Sciences 33:581-592

Feng L, Zhou T, Wu B, Li T, Luo J (2011) Projection of future precipitation change over China with a high-resolution global atmospheric model. Adv Atmos Sci 2:464-476

Gent PR, Yeager SG, Neale RB, Levis S, Bailey DA (2010) Improvements in a half degree atmosphere/land version of the CCSM. Clim Dyn 34:819-833

Huang R, Xu Y, Zhou L (1999) The interdecadal variation of summer precipitations in China and the drought trend in North China (in Chinese). Plateau Meteorology 18:465-476

Kalnay E et al (1996) The NCEP/NCAR 40-year reanalysis project. Bull Am Meteorol Soc 77:437-471

Kuang X, Zhang Y (2006) Impact of the position abnormalities of East Asian subtropical westerly jet on summer precipitation in middlelower reaches of Yangtze River (in Chinese). Plateau Meteorology 25:382-389

Kusunoki S, Yoshimura J, Yoshimura H, Noda A, Oouchi K, Mizuta R (2006) Change of Baiu rain band in global warming projection by an atmospheric general circulation model with a $20-\mathrm{km}$ grid size. Journal of the Meteorological Society of Japanserii 84:581-611

Kwon MH, Jhun JG, Wang B, An SI, Kug JS (2005) Decadal change in relationship between east Asian and WNP summer monsoons. Geophys Res Lett 32:101-120

Lau NC, Ploshay JJ (2009) Simulation of synoptic- and subsynoptic-scale phenomena associated with the East Asian summer monsoon using a high-resolution GCM. Monwearev 137:137

Li J, Zeng Q (2002) A unified monsoon index. Geophysical Research Letters 29:115-111-115-114

Li H, Dai A, Zhou T, Lu J (2010) Responses of East Asian summer monsoon to historical SST and atmospheric forcing during 1950 2000. Clim Dyn 34:501-514

Li J, Yu R, Yuan W, Chen H, Sun W, Zhang Y (2015) Precipitation over East Asia simulated by NCAR CAM5 at different horizontal resolutions. Journal of Advances in Modeling Earth Systems 7:774-790

Lin JL et al (2008) Subseasonal variability associated with Asian summer monsoon simulated by 14 IPCC AR4 coupled GCMs. J Clim 21: $4541-4567$

Menon S, Hansen J, Nazarenko L, Luo Y (2002) Climate effects of black carbon aerosols in China and India. Science 297:2250-2253

Mlawer EJ, Taubman SJ, Brown PD, Iacono MJ, Clough SA (1997) Radiative transfer for inhomogeneous atmospheres: RRTM, a validated correlated-k model for the longwave. J Geophys Res 102: $16663-16682$

Morrison H, Gettelman A (2008) A new two-moment bulk stratiform cloud microphysics scheme in the community atmosphere model, version 3 (CAM3). Part I: description and numerical tests. J Clim 21: 3642-3659

Neale R (2010) Description of the NCAR Community Atmospheric Model (CAM5. 0), NCAR/TN 4861STR.

Park S, Bretherton CS, Rasch PJ (2014) Integrating cloud processes in the community atmosphere model, version 5. J Clim 27:6821-6856 
Qian Y, Giorgi F (1999) Interactive coupling of regional climate and sulfate aerosol models over eastern Asia. Journal of Geophysical Research Atmospheres 104:6477-6499

Ramaswamy V et al (2001) Stratospheric temperature trends: observations and model simulations. Rev Geophys 39:71-122

Richter JH, Rasch PJ (2008) Effects of convective momentum transport on the atmospheric circulation in the community atmosphere model, version 3. J Clim 21:1487-1499

Song F, Zhou T, Qian Y (2014) Responses of East Asian summer monsoon to natural and anthropogenic forcings in the 17 latest CMIP5 models. Geophys Res Lett 41:596-603

Sperber KR et al (2013) The Asian summer monsoon: an intercomparison of CMIP5 vs. CMIP3 simulations of the late 20th century. Clim Dyn 41:2711-2744

Sun Y, Ding Y (2008) Validation of IPCC AR4 climate models in simulating interdecadal change of East Asian summer monsoon (in Chinese). Acta Meteorologica Sinica 66(5):765-780

Trenberth KE, Fasullo JT (2013) An apparent hiatus in global warming? Earth's Future 1:19-32

Trenberth KE, Fasullo JT, Branstator G, Phillips AS (2014) Seasonal aspects of the recent pause in surface warming. Nature Clim Change. Advance online publication doi:10.1038/nclimate2341 http://www.nature.com/nclimate/journal/vaop/ncurrent/abs/ ?nclimate2341.html\#supplementary-information

Turner AG, Slingo JM, Sperber K, Meehl G, Mechoso CR, Kimoto M, Giannini A (2008) Modelling monsoons: understanding and predicting current and future behaviour. World Scientific/wmo

Wang S (1994) Diagnostic studies on the climate change and variability for the period of 1880-1990 (in Chinese). Acta Meteorologica Sinica 52:261-273

Wang S (1997) Scientific intersection of PAGES and CLIVAR (in Chinese). Acta Meteorologica Sinica 55:662-669

Wang H (2001) The weakening of the Asian monsoon circulation after the end of 1970's. Adv Atmos Sci 18:376-386

Wang B, Ding Q, Fu X, Kang IS, Jin K, Shukla J, Francisco DR (2005) Fundamental challenge in simulation and prediction of summer monsoon rainfall. Geophys Res Lett 32(15):291-310

Wang B, Bao Q, Hoskins B, Wu G, Liu Y (2008) Tibetan plateau warming and precipitation changes in East Asia. Geophys Res Lett 35:63-72

Wu R, Wang B (2002) A contrast of the East Asian summer monsoonENSO relationship between 1962 and 77 and 1978-93. J Clim 15: 3266-3279

Xin X, Yu R, Zhou T, Wang B (2006) Drought in late spring of South China in recent decades. Journal of Climate 19

Xin X, Zhou T, Yu R (2010) Increased Tibetan Plateau snow depth: an indicator of the connection between enhanced winter NAO and late- spring tropospheric cooling over East Asia. Adv Atmos Sci 27:788794

Yu R, Zhou T (2004) Impacts of winter-NAO on March cooling trends over subtropical Eurasia continent in the recent half century. Geophys Res Lett 31:261-268

Yu R, Zhou T (2007) Seasonality and three-dimensional structure of interdecadal change in the East Asian monsoon. Journal of Climate 20

Yu R, Li W, Zhang X, Liu Y, Yu Y, Liu H, Zhou T (2000) Climatic features related to eastern China summer rainfalls in the NCAR CCM3. Adv Atmos Sci 17:503-518

Yu R, Wang B, Zhou T (2004) Tropospheric cooling and summer monsoon weakening trend over East Asia. Geophysical Research Letters 31 doi:10.1029/2004GL021270

Yuan W, Li J, Yu R, Zhang M, Lin W, Fu Y (2013) Diurnal cycle of summer precipitation over subtropical East Asia in CAM5. J Clim 26:3159-3172

Zhang GJ, McFarlane NA (1995) Sensitivity of climate simulations to the parameterization of cumulus convection in the Canadian Climate Centre general circulation model. Atmosphere-Ocean 33:407-446

Zhang Q, Wei J, Tao S (2003) The decadal and interannual variations of drought in the northern China and association with the circulations (in Chinese). Climatic and Environmental Research 8:307-318

Zhao S, Li J, Yu R, Chen H (2015) Recent reversal of the uppertropospheric temperature trend and its role in intensifying the East Asian summer monsoon. Scientific Reports 5:11847. doi:10.1038 /srep 11847

Zhou T, Li Z (2002) Simulation of the East Asian summer monsoon using a variable resolution atmospheric GCM. Clim Dyn 19:167-180

Zhou T, Yu R (2006) Twentieth-century surface air temperature over China and the globe simulated by coupled climate models. J Clim 19:5843

Zhou T, Yu R, Li H, Wang B (2008) Ocean forcing to changes in global monsoon precipitation over the recent half-century. J Clim 21:38333852

Zhou T, Gong D, Li J, Li B (2009a) Detecting and understanding the multi-decadal variability of the East Asian summer monsoon-recent progress and state of affairs. Meteorol Z 18:455-467

Zhou T, Gong D, Li J, Li B (2009b) Detecting and understanding the multi-decadal variability of the East Asian summer monsoon-recent progress and state of affairs. Meteorologische Zeitschrift volume 18: $455-467(413)$

Zhou T et al (2009c) The CLIVAR C20C project: which components of the Asian-Australian monsoon circulation variations are forced and reproducible? Clim Dyn 33:1051-1068

Zhou TJ, Bo W, Wang B (2010) How well do atmospheric general circulation models capture the leading modes of the interannual variability of the Asian-Australian monsoon? J Clim 22:1159-1173 